\title{
Changes in the Practice of Electroconvulsive Therapy in Poland: A Nationwide Survey Comparing Data Between 2005 and 2020
}

This article was published in the following Dove Press journal: Neuropsychiatric Disease and Treatment

\author{
Anna Z Antosik- \\ Wójcińska ${ }^{1,2}$ \\ Monika Dominiak iD ${ }^{2,3}$ \\ Paweł Mierzejewski ${ }^{2,3}$ \\ Piotr Jażdżyk ${ }^{4,5}$ \\ Gabor Gazdag 6,7 \\ Rozalia Takacs 8,9 \\ Adam Wichniak ${ }^{2,10}$ \\ 'Department of Psychiatry, Medical \\ University of Warsaw, Warsaw, Poland; \\ ${ }^{2}$ Section of Biological Psychiatry of the \\ Polish Psychiatric Association, Institute of \\ Psychiatry and Neurology, Warsaw, \\ Poland; ${ }^{3}$ Department of Pharmacology, \\ Institute of Psychiatry and Neurology, \\ Warsaw, Poland; ${ }^{4}$ Institute of Psychiatry \\ and Neurology, Warsaw, Poland; ${ }^{5}$ Chair \\ and Department of Experimental and \\ Clinical Physiology, Laboratory of Centre \\ for Preclinical Research, Medical \\ University of Warsaw, Warsaw, Poland; \\ ${ }^{6}$ Department of Psychiatry and \\ Psychiatric Rehabilitation, Jahn Ferenc \\ South Pest Hospital, Budapest, Hungary; \\ ${ }^{7}$ Department of Psychiatry and \\ Psychotherapy, Faculty of Medicine, \\ Semmelweis University, Budapest, \\ Hungary; ${ }^{8}$ Psychiatric Outpatient Service, \\ Tóth Ilona Medical Service, Budapest, \\ Hungary; ' ${ }^{S}$ chool of Doctoral Studies, \\ Semmelweis University, Budapest, \\ Hungary; ${ }^{10}$ Third Department of \\ Psychiatry, Institute of Psychiatry and \\ Neurology, Warsaw, Poland
}

Correspondence: Monika Dominiak Department of Pharmacology, Institute of Psychiatry and Neurology, ul. Sobieskiego 9, Warsaw, PL-02957, Poland

$\mathrm{Tel} / \mathrm{Fax}+48228427644$

Email mdominia@wp.pl
Background: The use and the characteristics of the practice of electroconvulsive therapy (ECT) in Poland have not been evaluated since 2005, when a nationwide survey revealed its rare utilization ( 0.11 patients/10,000 inhabitants/year). The aims of this study were to determine the current use of ECT and to compare the findings with those of the previous survey.

Methods: Two questionnaires were sent to all 48 inpatient psychiatric centers in Poland. The first one - to units providing ECT to explore its practice, and the second - to units not performing ECT to explore the reasons for not using this treatment.

Results: Nineteen (39.6\%) of all psychiatric inpatient centers confirmed the use of ECT. The utilization rate was 0.13 patients/10,000 inhabitants. Similar to the findings from 2005 , the main indications were affective disorders, and bitemporal electrode placement was the dominant method used for the delivery of ECT. Age-based and titration-based methods were applied exclusively in $50 \%$ and $25 \%$ of the centers, respectively (compared with $15 \%$ and $35 \%$ in 2005 , respectively), while both methods were used in the remaining $25 \%$. Improvements in safety were reflected by the use of comprehensive pre-ECT evaluation and treatment monitoring. None of the centers used sine-wave devices; this contrasts with their use by $29 \%$ of the centers in 2005 . The main reasons for not using ECT were insufficient funding and a lack of experienced staff.

Conclusion: The frequency of ECT use in Poland remains very low. In view of the improvement in the quality of health services in the past decade, such a markedly rare use of an effective treatment was unexpected. There is an urgent need of education to create more positive attitude towards ECT among health professionals and among public, and to increase the training of mental health professionals in ECT.

Keywords: electroconvulsive therapy, survey, ECT utilization rate, ECT in Poland, ECT in central and eastern Europe

\section{Introduction}

Electroconvulsive therapy (ECT) remains the most effective treatment in severe and drug-resistant mental disorders. Poland has a fairly long, however, little known, history of using electric stimulation dating back to the 19th century. Although admittedly the most famous is the history of the treatment performed in 1938 by Italians Lucio Bini and Ugo Cerletti, ${ }^{1}$ the experiences of doctor Klemens Maleszewski, who in 1865 successfully used electric stimulation to induce seizure in the treatment of a patient with catatonia are well known in Poland. ${ }^{2}$ Maleszewski described this case, but the first description in an internationally indexed journal was published after more than a hundred years. ${ }^{3}$ 
Currently, there are approximately 1.4 million courses of ECT treatment delivered worldwide annually, with an estimated 2.34 patients treated per 10,000 inhabitants/year. The rates per 10,000 inhabitants range from 0.11 in Poland, to 0.26 in Germany, 0.31 in Hungary, 0.61 in Spain, 1.26 in Africa, 4.37 in Belgium and 5.10 in the US. ${ }^{4}$ Data for Poland is derived from the first nationwide survey on ECT practice that was performed in $2005 .{ }^{5}$ According to quoted review, ECT was used extremely rarely in Poland in 2005, placing this country at the far end of the list, not even in Europe, but all over the word. ${ }^{4}$ Further studies evaluating the use of ECT in CentralEastern European countries confirmed the low use of this method of treatment in the region. ${ }^{6-12}$ Poland also fell into these characteristics placing at the end of the list only ahead of Latvia, Ukraine and Serbia. ${ }^{6}$ This survey also provided information about inpatient psychiatric units performing ECT, as well as the considerable heterogeneity in their practice. ${ }^{5}$ These heterogeneities were related to the technical parameters of ECT, the main indications in which it was used, the safety of the ECT procedure, and the type of anesthetic agents that were used. Moreover, it has been shown, that in 5 units sine wave devices were still in use. At that time, the most frequently used electrode placement was bitemporal, unilateral procedures were performed only in one unit as a second choice treatment. The dominant use of bilateral ECT can be attributed to the historic view, quite strongly established in Poland, that these treatments are more effective than unilateral ones. $^{13,14}$

A large epidemiological study carried out in the last decade has indicated an increasing prevalence of mental disorders in the Polish population. ${ }^{15}$ This study estimated that at least one mental disorder (according to ICD-10 classification) can be diagnosed in $23.4 \%$ of the population during their lifetime. The percentage of affective disorders extrapolated to the entire population gave 1 million Poles possibly suffering from this condition. It is also worth quoting here data concerning one of the most important indicator - the rate of suicides, undoubtedly related to mental disorders. In comparison with the European Union countries, Poland is in ninth place from the end on the list of countries by suicide rate. This indicator, despite the large expenditures of the Polish government in the last decade on programs aimed at preventing depression and suicide, remains unchanged ranging from 13 to 14 per 100000 inhabitants per year. ${ }^{16}$
As it was in 2005, the Polish mental health system is based on large public psychiatric hospitals, where most psychiatric beds are located. There are currently 48 inpatient psychiatric centers (academic departments, psychiatric hospitals and psychiatric wards in general hospitals) containing a total of approximately 24,300 psychiatric beds. Poland has 4,274 specialist psychiatrists, ${ }^{17}$ but only approximately $50(1.2 \%)$ are currently performing ECT. According to the last census, Poland has nearly 38 millions of inhabitants. ${ }^{18}$

While in Western European countries (especially in Belgium, Spain, Germany) the availability of ECT has increased significantly in recent years, ${ }^{19-21}$ in CentralEastern Europe the situation in most countries has not changed or even worsened. ${ }^{6}$ Previous survey in 2005 in Poland has shown that the practice of ECT was definitely amenable for improvement. Since then, several initiatives to improve good clinical practice in this field were accomplished. In the last decade, the number of trainings of health professionals in ECT has slightly increased. Knowledge of ECT treatment has been also periodically presented at national psychiatric conferences by the specialists dealing with ECT on a daily basis. A significant step toward improving the quality of ECT provision was also the development of a national ECT treatment protocol in 2016 .

Regarding economic issues, although Poland is still classified as a middle-income country, the economic hindrances separating this country from Western European countries have significantly decreased over the last decade. An improvement in access to healthcare, especially for the private sector, and an increase in the quality of healthcare services were also noted in the last years.

There is no national database of ECT use in Poland, and there has been no systematic evaluation of ECT usage data in the last 15 years. To address this knowledge deficit, this study was designed to survey the practice of ECT in Poland.

\section{Materials and Methods}

In 2019, work was initiated by the Board of the Section of Biological Psychiatry, which is part of the Polish Psychiatric Association, to update data on psychiatric centers performing ECT in Poland. Information on the practice of ECT was sought from all inpatient psychiatric facilities (general hospitals, standalone psychiatric hospitals and academic departments). After e-mail and telephone verification, an updated list was created and 
published on the Polish Psychiatric Association website, comprising the names and contact details of all centers providing ECT. A 20-item semi-structured questionnaire was sent to all psychiatric centers that were performing ECT. We used the original version of the questionnaire developed by Hungarian researchers and utilized it in surveys performed in other European countries. ${ }^{22}$ Authors of original version gave permission for its translation, adaptation and usage. The questionnaire asked about the number, sex, and diagnostic distribution of patients, the special populations treated with ECT (children/adolescents, the elderly, and pregnant women), the provision of maintenance ECT, and the technical parameters of the ECT used (the type of device, the current, and the electrode placement used; the methods used to determine the electrical charge; the number of courses and sessions; the monitoring of the procedure; and the minimum length of effective seizure). Additional questions were asked about the type of general anesthetics that were used medications, and the pre-treatment evaluation (Appendix 1).

A second questionnaire was also sent to those centers where ECT was not practiced. The aim of this questionnaire was to determine the reasons for not using ECT (Appendix 1).

Both questionnaires were sent by email to the relevant psychiatric centers in early January 2020. Centers that failed to reply after 6 weeks were sent a second email and were contacted by telephone to ascertain if they had received the questionnaires. After 4 more weeks, centers that had not responded were phoned again, to repeat the request for information. At this time, the SARS-CoV-2 epidemic broke out and some of these units were transformed into treatment facilities for psychiatric COVID-19 patients. During a telephone contact, a problem with access to statistical data needed to fill in the survey was reported by several units. Eventually, in late June 2020, the epidemic situation began to normalize and the last questionnaires were obtained.

The study was notified to the Bioethics Committee at the Institute of Psychiatry and Neurology in Warsaw. A formal approval of the Bioethics Committee was not required as it was a questionnaire surveys not endangering the well-being and interests of the patient and not interfering with his or her privacy.

\section{Statistical Analysis}

Descriptive statistics were performed with the Statistica 12.0 software package (StatSoft, Inc., Tulsa, OK, USA).
Data were reported as means and standard deviations (SDs) or percentages, as appropriate.

\section{Results}

Thirty-seven centers replied to the questionnaire, yielding a response rate of $77 \%$. Twenty-two centers $(45.8 \%)$ confirmed their use of ECT in general, but only 19 (39.6\%) had actually performed ECT in 2019. Sixteen centers of the latter group (84.2\%) returned a completed questionnaire, while three centers refused or were unable to complete the questionnaire.

The calculated rate of ECT use was 0.13 patients treated per 10,000 inhabitants-year. The number of patients who received ECT ranged between 1 and 88 across the centers. In the centers that provided ECT, the percentage of inpatients that were treated varied from $0.001 \%$ to $7.3 \%$ of all admissions. Maintenance ECT was available in nine $(56 \%)$ of the centers and was offered to approximately $16.7 \%$ of all ECT-treated patients.

Sixty-one percent of the patients undergoing ECT were women. The main indications for receiving ECT were bipolar depression (47.5\%), schizophrenia (26.5\%), and unipolar depression (22\%). ECT was also provided to patients with mania $(1.2 \%)$, organic mood disorder, schizoaffective disorder (1\%), neuroleptic malignant syndrome $(0.2 \%)$, and obsessive-compulsive disorder $(0.2 \%)$. Three centers $(18.7 \%)$ offered ECT to patients under 18; pregnant women were treated in 11 centers $(68.7 \%)$, and in 14 centers $(87.5 \%)$ ECT was also used in elderly ( $>70$-yearold) patients.

The number of sessions per course ranged between 8 and 15 , with a mean of 11.3 (SD 2.3); the highest number of sessions was 20. Eight (50\%) and 7 (43.7\%) centers administered ECT twice and three times a week, respectively, and in one center $(6.2 \%)$ ECT was performed 2 or 3 times a week.

Bitemporal electrode position was the dominant ECT technique used in 15 centers $(93.7 \%)$. The unilateral stimulation was used as a first choice in only one center $(6.2 \%)$ and used in exceptional circumstances in another 4 centers $(25 \%)$. In 4 centers $(25 \%)$, the bifrontal electrode position was also used.

Eleven centers $(68.7 \%)$ used the Thymatron System IV instrument and 5 (31.2\%) used the Mecta Spectrum 5000 Q device. Sine-wave machines were no longer in use in 2020. A brief-pulse wave current technique was routinely used in 14 centers $(87.5 \%)$ and an ultra-brief-pulse current 
technique was the only technique used in 2 centers $(12.5 \%)$, and was used as an additional option in 1 center $(6.2 \%)$.

Electroencephalographic (EEG) monitoring was available in all units. ECT machines, which also perform electromyographic registration were available in 4 settings (25\%). Twelve centers (75\%) used both electroencephalogram and visual observation to monitor seizure duration. The cuff limb technique was used as an additional observational technique in 4 centers $(25 \%)$.

The lowest threshold for an effective seizure duration was between 20 and 35 seconds. Twenty seconds was regarded as the minimal sufficient duration of seizure in 6 centers $(37.5 \%), 25$ seconds in another 3 centers $(18.7 \%), 30$ seconds in another 5 centers $(31.2 \%)$, and 35 seconds in one center $(6.2 \%)$.

The stimulus intensity was set according to the agebased method in 8 centers $(50 \%)$, while the stimulus was titrated in another 4 centers $(25 \%)$. Both methods were used to induce a seizure in 4 other centers $(25 \%)$.

Propofol, etomidate, thiopental and ketamine were the anesthetic agents of choice in $13(81.2 \%), 8(50 \%), 5$ $(31.2 \%)$ and 4 (25\%) centers, respectively. Succinylcholine was applied as myorelaxant in 11 (68.7\%) facilities and atropine was administrated before ECT treatments in $3(18.7 \%)$ units.

Routine pre-ECT evaluations were examination by a physician $(\mathrm{n}=15,93.7 \%)$ and/or a neurologist $(\mathrm{n}=13$, $81.2 \%)$. Ophthalmologic $(\mathrm{n}=10,62.5 \%)$ and anesthesiologic examinations $(\mathrm{n}=12,75 \%)$, electroencephalogram (EEG; $n=11,68.7 \%$ ), computerized tomography or magnetic resonance scans $(\mathrm{n}=13,81.2 \%)$ were mandatory, while carotid doppler ultrasonography was the preferred pre-ECT investigation in one center $(6.2 \%)$.

The second questionnaire was completed by 21 (72.4\%) of the 29 centers where ECT was currently not available. All but one center (95\%) considered that ECT remained a valuable therapeutic method, and all of these facilities referred patients to other centers to receive ECT. The reasons stated for not applying ECT were as follows: insufficient funding $(\mathrm{n}=18,85.7 \%)$, lack of experienced staff to administer ECT $(\mathrm{n}=19,90.4 \%)$, unavailability of an anesthesiologist $(\mathrm{n}=15,71.4 \%)$, and the lack of an ECT machine $(\mathrm{n}=18,80.9 \%)$.

\section{Discussion}

The main finding of this study is the persistence of a very low utilization rate of ECT in Poland in 2019. The rate has increased only slightly from 0.11 patients/10,000 inhabitants in 2005 to 0.13 patients $/ 10,000$ inhabitants in 2019. These rates place Poland at the lower end of the list of countries that practice ECT. ${ }^{4,6,23}$ This result seems very surprising given both the country's economic growth, the improvement in quality and accessibility of health services and the increased investment in health care that was seen over the last decade. However, it appears that public mental health care, including the ECT procedure, has not been strongly affected by these positive changes. In 2005 ECT was available in 25 centers in Poland, ${ }^{5}$ at present treatments are performed in only 19 units, thus, the percentage of psychiatric facilities providing ECT was reduced from $43.1 \%$ to $39.6 \%$. Furthermore, in 6 $(37.5 \%)$ centers fewer than 10 patients received ECT in 2019. Such a rare use of ECT diminishes the proficiency of staff and, consequently, decreases their ability to provide ECT. Only four centers, all of which are large research or academic centers located in central Poland, treated more than 50 patients in 2019; they accounted for $62.3 \%$ of all patients that received ECT in the country. This may be attributable to the fact that ECT is a relatively expensive treatment modality that requires the collaboration of highly trained and experienced professionals, and it may therefore be infeasible for smaller psychiatric centers to use $\mathrm{ECT}^{8}{ }^{8}$ Thus, a logical solution for increasing the availability of ECT in a relatively small country with good transport, such as Poland, may be to centralize ECT provision.

Fifteen years after the first survey, there is no difference regarding electrode placement (Table 1). Bilateral ECT remains the dominant technique in all but one center, despite the well-established benefits of unilateral stimulation in terms of tailoring the ECT method for each patient. ${ }^{24-26}$ For stimulus dosing, most centers use currently the age-based method. In this respect there is also a room for further improvement as most guidelines indicate titration-based methods as the most beneficial in determining seizure threshold. ${ }^{26-28}$ In line with the findings of the 2005 survey and with its practice in other European and developed countries, ${ }^{4,19,21}$ ECT was indicated mostly for the treatment of affective disorders. In addition, a positive aspect of ECT provision in Poland that was identified is the improvement in the safety measures since 2005. This is reflected by sine-wave devices no longer being used in any centers, what is in line with current standards ${ }^{26-28}$ (in 2005 they were used in $29 \%$ of units). Moreover, EEG monitoring of seizure duration is now used in all centers, whereas $32 \%$ of the centers failed 
Table I Results of the Nationwide Surveys in 2005 and 2020 in Poland

\begin{tabular}{|c|c|c|c|c|}
\hline Outcomes & \multicolumn{2}{|r|}{2005} & \multicolumn{2}{|r|}{2020} \\
\hline ECT rate (patients treated per/ 10,000 inhabitants per year) & \multicolumn{2}{|r|}{0.11} & \multicolumn{2}{|c|}{0.13} \\
\hline Units performing ECT n (\%) & \multicolumn{2}{|c|}{$25(43.1 \%)$} & \multicolumn{2}{|c|}{$19(39.6 \%)$} \\
\hline Maintenance ECT n (\%) & \multicolumn{2}{|r|}{$5(25 \%)$} & \multicolumn{2}{|c|}{$9(56 \%)$} \\
\hline Percent of ECT-treated patients receiving maintenance ECT & \multicolumn{2}{|r|}{$25-35 \%$} & \multicolumn{2}{|r|}{$16.7 \%$} \\
\hline Main indications & \multicolumn{2}{|c|}{ Affective disorders } & \multicolumn{2}{|c|}{ Affective disorders } \\
\hline Sex distribution $F / M$ & \multicolumn{2}{|c|}{$65 \% / 35 \%$} & \multicolumn{2}{|c|}{$61 \% / 39 \%$} \\
\hline \multicolumn{5}{|l|}{ Anaesthetics n (\%) } \\
\hline Propofol & \multicolumn{2}{|r|}{$6(30 \%)$} & \multicolumn{2}{|c|}{$13(81.2 \%)$} \\
\hline Etomidate & \multicolumn{2}{|r|}{$4(20 \%)$} & \multicolumn{2}{|r|}{$8(50 \%)$} \\
\hline Ketamine & \multicolumn{2}{|r|}{0} & \multicolumn{2}{|r|}{$4(25 \%)$} \\
\hline Thiopental & \multicolumn{2}{|r|}{15 (75\%) } & \multicolumn{2}{|c|}{$5(31.2 \%)$} \\
\hline \multicolumn{5}{|l|}{ Stimulus dosing method $\mathbf{n}(\%)$} \\
\hline Always dose titration & \multicolumn{2}{|r|}{$7(35 \%)$} & \multicolumn{2}{|r|}{$4(25 \%)$} \\
\hline Always age-based method & \multicolumn{2}{|r|}{$3(15 \%)$} & \multicolumn{2}{|r|}{$8(50 \%)$} \\
\hline Different techniques & \multicolumn{2}{|c|}{ Data unavailable } & \multicolumn{2}{|r|}{$4(25 \%)$} \\
\hline Fixed dose & \multicolumn{2}{|r|}{$10(50 \%)$} & \multicolumn{2}{|r|}{0} \\
\hline Monitoring of ECT treatments n (\%) & & & & \\
\hline Visual only & & $9(45 \%)$ & & 0 \\
\hline EEG + cuff & & a unavailable & & $4(25 \%)$ \\
\hline EEG & & II (55\%) & & $6(100 \%)$ \\
\hline ECT device n (\%) & & & & \\
\hline Sine wave & & $5(29.4 \%)$ & & 0 \\
\hline Brief pulse & & $2(70.5 \%)$ & & $4(87.5 \%)$ \\
\hline Ultra brief pulse & & 0 & & $(18.7 \%)$ \\
\hline Electrode placement n (\%) & Dominant & Exceptionally used & Dominant & Exceptionally used \\
\hline Bitemporal & $20(100 \%)$ & & $15(93.7 \%)$ & \\
\hline Bifrontal & 0 & $\mathrm{I}(5 \%)$ & 0 & $4(25 \%)$ \\
\hline Unilateral & 0 & I (5\%) & I (6.2\%) & $4(25 \%)$ \\
\hline
\end{tabular}

to monitor seizure duration with EEG in 2005. Compared to 2005, present-day pre-treatment evaluation is much more uniform across the centers. ECT was performed under general anesthesia in all centers. Propofol was the most frequently used anesthetic agent (in $81.2 \%$ of the centers), in contrast to its minority use in 2005 (24\%). This is in line with the literature that suggests that propofol is superior to thiopental in terms of tolerability (cognitive side effects). ${ }^{29}$ However, the discussion about the most optimal anaesthetic for ECT treatments is still ongoing in the literature. ${ }^{30}$

There are several possible explanations for the low utilization rate of ECT. In general, in Poland, ECT is under-funded and its application requires hospitalization.
Furthermore, in Poland (as well as in Hungary) ECT is still considered as an invasive procedure, patients must give written informed consent before it can be supplied. Nevertheless, Kellner et $\mathrm{al}^{31}$ argued that ECT is indeed a noninvasive procedure as it does not meet the criteria set out in the medical definition of the term "invasive procedure". Such a misleading categorization may aggravate the negative perception of this method of treatment. ${ }^{31}$

In cases where a patient's life is in immediate danger and $\mathrm{s} /$ he is unable to give consent, a court must approve ECT. Another issue that makes the wider use of ECT even more complicated, could be the fact that Polish National Health Fund (NHF) pays only for ECT treatment delivered to severely ill patients in life-threatening condition. 
One of the strengths of this survey is that it considered both active centers and those centers that were not currently performing ECT. The most frequently mentioned reasons for not providing ECT were organizational and funding constraints, as well as a lack of qualified personnel. Other reasons, which were related to the poor financial situation of certain centers, included a lack of access to anesthesiologists or to the necessary equipment.

Over the past decade, a great deal of effort has been made in Poland to disseminate the use of ECT and address the organizational and legal aspects of its implementation. Since 2016, a national ECT protocol has been available that includes standard forms for informed consent, information on ECT and a proposed list of patient's variables to be monitored during treatment (patients' card). These standard forms are currently in use by all centers in Poland that perform ECT. Furthermore, every psychiatric resident must perform at least 2 sessions of ECT. Updated information about ECT is also distributed at annual national psychiatric conferences by experienced practitioners. To date, however, no formalized ECT-focused educational courses or training schemes have been developed. The common practice remans "bedside teaching", during which experienced psychiatrists share their knowledge informally with interested new staff members.

However, the results of this survey indicate that the actions taken in the last years to disseminate and regulate the ECT practice are clearly insufficient. Based on the findings of this survey, we make the following recommendations for improving the use of ECT in Poland. The most urgent task is the development of evidence-based ECT training for mental health professionals. This should be accompanied by the preparation of an updated textbook, as the source of information on ECT in Poland is currently limited to a few rather outdated textbooks. ${ }^{32,33}$ The low popularity of and insufficient knowledge about ECT also restrict its widespread use. ${ }^{34}$ The problem of the low popularity of ECT and insufficient knowledge about this method was highlighted in a survey conducted among medical personnel. ${ }^{34}$ The results clearly indicated that work in a centre where ECT is performed or the possibility to participate in such a procedure readily translates into favorable attitudes and the higher frequency of referring patients to ECT. Also, in other studies, it has been demonstrated that training in ECT would promote its utilization and improve the quality of its practice. ${ }^{35}$ The other problem is the lack of comprehensive national guidelines that could enhance the quality of ECT practice. However,
Polish unified recommendations on the practice of ECT treatment are currently being developed by a group of experts appointed by the Section of Biological Psychiatry of the Polish Psychiatric Association. A national database covering all aspects of ECT should be also established, as a systematic evaluation of data related to all aspects of ECT could translate into a more positive attitude towards this treatment modality. Based on the experiences of other countries, ${ }^{19}$ ECT could be further promoted by providing comprehensive information for patients and their families through the media and in the form of leaflets in psychiatric units. Such information, including the effectiveness, safety and tolerability could familiarize with ECT and address patients' concerns.

Currently, ECT is rarely used in Poland, even compared to other Central-East European countries that are economically and socio-culturally similar to Poland. The Polish data definitely do not fit into the upward trend seen in Western Europe, although economically and in terms of the quality of health services the country has moved much closer to Western European countries. For comparison: in the Czech Republic, the country that is a direct neighbor of Poland, belonging to the same cultural circle, where the mental health system is similar to polish one and concentrated in large units, the use of ECT is very high ( 1 per 10,000 inhabitants/year). ${ }^{36}$ One of the factors influencing the greater use of this method in Czech Republic could be the availability of national guidelines issued by the Czech Psychiatric Society. ${ }^{36}$ Procedures in all centers follow these national guidelines. Obviously, there are a multitude of social, cultural, financial and organizational factors influencing the availability of ECT in given country. Nevertheless, the conclusions from this study could also be, to some extent, considered as valuable in other countries with low utilization of ECT, especially in central and eastern Europe.

\section{Limitation}

The study has a number of limitations. Similar to the situation in 2005, the present survey relied on answers provided by the heads of services in ECT centers. Also, $28 \%$ of centers where ECT was not performed did not provide answers to the questionnaire, which limits the generalizability of the findings.

\section{Conclusions}

The current use of ECT in Poland remains extremely rare, suggesting that an unknown percentage of Polish patients 
may not have access to an effective (and often life-saving) treatment. As indicated above, the provision of ECT remains a significant economic burden for smaller hospitals, thus, the centralization of expertise in fewer, specialized treatment facilities should be considered as a solution. In line with other publications authors indicate also that more education and training on ECT are warranted to create a more positive attitude towards ECT among mental health professionals and among public. ${ }^{34}$ There is also an urgent need to develop national guidelines addressing the ECT provision.

\section{Acknowledgments}

The authors thank all colleagues who replied to the questionnaires.

\section{Disclosure}

The authors report no conflicts of interest in this work.

\section{References}

1. Cerletti U, Bini L. Un nuovo metodo di shockterapie: 'l' elettroshock' (riassunto). Reale Accademia Medica (Communicazione alla seduta del 28 maggio 1938- XVI della, Reale Accademia Medica di Roma.), Rome. 1938.

2. Nasierowski T. Rękopis znaleziony w Wilnie. Opis zespołu katatonicznego u Marcina Merczysa, pacjenta Wileńskiego Zakładu Obłąkanych, wraz z opisem podjętej, najprawdopodobniej po raz pierwszy w historii psychiatrii, próby leczenia katatonii prądem elektrycznym, dokonany przez wileńskiego psychiatrę Klemensa Maleszewskiego (The manuscript found in Vilnius. Description of the catatonia in Marcin Merczys, a patient of Vilnius Insane Asylum, with a description of an attempt by Vilnius psychiatrist Klemens Maleszewski to treat catatonia with electric current, probably for the first time in the history of psychiatry) [Polish] Terapia. 1998;3:29-30.

3. Nasierowski T. Klemens Maleszewski - pionier terapii elektrowstrząsowej w psychiatrii polskiej (Klemens Maleszewski pioneer of electroconvulsive therapy in Polish psychiatry) [Polish]. Psych Pol. 2002;36(2):259-269.

4. Leiknes KA, Jarosh-von Schweder L, Hoie B. Contemporary use and practice of electroconvulsive therapy worldwide. Brain Behav. 2012;2:283-344. doi:10.1002/brb3.37

5. Palinska D, Gazdag G, Sobow T, Hese RT, Kloszewska I. Electroconvulsive therapy in Poland in 2005-a nationwide questionnaire study performed in Polish psychiatric clinics [Polish]. Psychiatr Pol. 2008;42:825-839.

6. Gazdag G, Dragasek J, Takács R, et al. Use of electroconvulsive therapy in central-eastern European countries: an overview. Psychiatr Danub. 2017;29(2):136-140. doi:10.24869/psyd.2017.136

7. Lõokene M, Kisuro A, Mačiulis V, et al. Use of electroconvulsive therapy in the Baltic states. World J Biol Psychiatry. 2014;15:419-424. doi:10.3109/15622975.2013.866692

8. Hranov LG, Hranov G, Ungvari GS, Gazdag G. Electroconvulsive therapy in Bulgaria: a snapshot of past and present. $J$ ECT. 2012;28 (2):108-110. doi:10.1097/YCT.0b013e318245ca05

9. Asztalos M, Ungvari GS, Gazdag G. Changes in electroconvulsive therapy practice in the last 12 years in Hungary. $J$ ECT. 2017;33 (4):260-263. doi:10.1097/YCT.0000000000000428
10. Olekseev A, Ungvari GS, Gazdag G. Electroconvulsive therapy practice in Ukraine. $J$ ECT. 2014;30:216-219. doi:10.1097/ YCT.000000000000084

11. Spiric Z, Stojanovic Z, Samardzic R, Milovanović S, Gazdag G, Marić NP. Electroconvulsive therapy practice in Serbia today. Psychiatr Danub. 2014;26:66-69.

12. Nelson AI. A national survey of electroconvulsive therapy use in the Russian Federation. J ECT. 2005;21:151-157. doi:10.1097/01. yct.0000172569.44675.53

13. Zyss T, Hese RT, Zięba A. Terapia wstrząsowa w psychiatrii- rys historyczny (Electroconvulsive therapy in psychiatry - historical background) [Polish]. Psychiatria Pol. 2008;42:797-818.

14. UK ECT Review Group. Efficacy and safety of electroconvulsive therapy in depressive disorders: a systematic review and meta-analysis. Lancet. 2003;361:799-808. doi:10.1016/S0140-6736(03)12705-5

15. Moskalewicz J, Kiejna A, Wojtyniak B. Kondycja psychiczna mieszkańców Polski: raport $\mathrm{z}$ badań "Epidemiologia zaburzeń psychiatrycznych i dostęp do psychiatrycznej opieki zdrowotnej - EZOP Polska" (Mental condition of Polish residents: research report "Epidemiology of psychiatric disorders and access to psychiatric health care - EZOP Poland") [Polish]. Warszawa: Instytut Psychiatrii i Neurologii; 2012.

16. WHO. Suicide rates data by country. 2016.

17. Statistics Poland. Health and health care in 2018.

18. Statistics Poland. Demographic yearbook of Poland. 2019.

19. Sienaert P, Falconieri T, Obbels J, et al. Improving practice in electroconvulsive therapy: a nationwide survey in Belgium. J ECT. 2016;32:29-32. doi:10.1097/YCT.0000000000000260

20. Vera I, Sanz-Fuentenebro J, Urretavizcaya M, et al. Electroconvulsive therapy practice in Spain: a national survey. $J$ ECT. 2016;32(1):5561. doi: 10.1097/YCT.0000000000000270

21. Loh N, Nickl-Jockschat T, Sheldrick AJ, Grözinger M. Accessibility, standards and challenges of electroconvulsive therapy in Western industrialized countries: a German example. World $J$ Biol Psychiatry. 2013;14(6):432-440. doi:10.3109/15622975.20 12.665176

22. Gazdag G, Kocsis N, Lipcsey A. Rates of electroconvulsive therapy use in Hungary in 2002. $J$ ECT. 2004;20:42Y44. doi:10.1097/ 00124509-200403000-00009

23. Lessage A, Lemasson M, Medina K, et al. The prevalence of electroconvulsive therapy use since 1973: a meta-analysis. $J E C T$. 2016;32:236-242. doi:10.1097/YCT.0000000000000320

24. Sackeim HA, Prudic J, Nobler MS, et al. Effects of pulse width and electrode placement on the efficacy and cognitive effects of electroconvulsive therapy. Brain Stimul. 2008;1:71-83. doi:10.1016/j. brs.2008.03.001

25. Kolshus E, Jelovac A, McLoughlin DM. Bitemporal v. high-dose right unilateral electroconvulsive therapy for depression: a systematic review and meta-analysis of randomized controlled trials. Psychol Med. 2017;47(3):518-530. doi:10.1017/S0033291716002737

26. Weiss A, Hussain S, Ng B, et al. Royal Australian and New Zealand College of Psychiatrists professional practice guidelines for the administration of electroconvulsive therapy. Aust $N Z$ J Psychiatry. 2019;53(7):609-623. doi:10.1177/0004867419839139

27. American Psychiatric Association. The Practice Of Electroconvulsive Therapy: recommendations for treatment, training, and privileging. Washington, DC: American Psychiatric Publishing; 2001:158161.

28. NICE. Depression: the treatment and management of depression in adults. NICE Clinical Guideline. London: National Institiute for Health and Clinical Excellence; 2009.

29. Bauer J, Hageman I, Dam H, et al. Comparison of propofol and thiopental as anesthetic agents for electroconvulsive therapy: a randomized, blinded comparison of seizure duration, stimulus charge, clinical effect, and cognitive side effects. J ECT. 2009;25:85-90. doi:10.1097/YCT.0b013e31818a0203 
30. Soehle M, Bochem J. Anesthesia for electroconvulsive therapy. Curr Opin Anaesthesiol. 2018;31(5):501-505. doi:10.1097/ACO.0000 000000000624

31. Kellner CH, Greenberg RM, Petrides G, Ahle GM, Adams DA, Liebman LS. Electroconvulsive therapy is a noninvasive brain stimulation technique. $J$ ECT. 2016;32(1):70. doi:10.1097/YCT.0000 000000000255

32. Krzyżanowski J. Leczenie Elektrowstrząsami (Electroconvulsive therapy) [Polish]. Warszawa: LogoScript Sp. z o.o; 1991.

33. Hese RT. Miejsce elektrowstrząsowej we wspołczesnej terapii psychiatrycznej (The place of electroconvulsive therapy in modern therapy of mental disorders) [Polish]. Psychiatria. 2007;1:30-36.
34. Antosik-Wójcińska A, Gazdag G, Święcicki Ł, et al. Attitudes towards ECT: a survey of polish mental health professionals. Psychiatr Danub. 2020. doi:10.31219/osf.io/7xuke

35. Oldewening K, Lange RT, Willan S, et al. Effects of an education training program on attitudes to electroconvulsive therapy. $J E C T$. 2007;23:83-88. doi:10.1097/YCT.0b013e3180421a0a

36. Kalisowa L, Madlova K, Albrecht J, et al. Electroconvulsive therapy in the Czech Republic. J ECT. 2018;34(2):108-112. doi:10.1097/ YCT.0000000000000466

\section{Publish your work in this journal}

Neuropsychiatric Disease and Treatment is an international, peerreviewed journal of clinical therapeutics and pharmacology focusing on concise rapid reporting of clinical or pre-clinical studies on a range of neuropsychiatric and neurological disorders. This journal is indexed on PubMed Central, the 'PsycINFO' database and CAS, and is the official journal of The International Neuropsychiatric Association (INA). The manuscript management system is completely online and includes a very quick and fair peer-review system, which is all easy to use. Visit http://www.dovepress.com/testimonials.php to read real quotes from published authors. 